\title{
Research on Hot Decomposition and Burn Function of a Double Base Propellant
}

\author{
H.C. WANG \\ Ordnance Engineering College, Hebei Shijiazhuang, 050003, China \\ M.H. CHEN \& S. YUAN \\ Ordnance Institute of Technology, Hebei Shijiazhuang, 050003, China
}

Y.W. FAN

Jiangyang Company, Jinxi Industrial Group, Taiyuan 030041, China

\begin{abstract}
DSC method and closed bomb test were adopted to an aging different time of the double base propellant forward to carry on a research, activate energy was computed with dynamics method, and computing synthesize combustion characteristic parameter of the double base propellant. Conclusion: with aging time longer, activate energy of double base propellant was decrease, the burn function descends

KEYWORD: Double base propellant, DSC, Closed bomb test, Kinetics of thermal analysis method
\end{abstract}

\section{INTRODUCTION}

A double radicles push forward one even structure, the production craft mature, cheap cost and various function emersion good, store life span to grow, not sensitive to moisture, have no smoke, quality stability, production the period is small. It still hasn't commutable position in some motors [HU R.Z, 2013]. Therefore, push forward to study the hot decomposition and combustion function of the double radicle, this literary adopted aging the double base propellant with $85^{\circ} \mathrm{C}$ conditions, experiment with DSC that the dissimilarity heats velocity to aging not and meantime of the double radicle push forward the hot decomposition process of to carry on an examination, computing the activate energy and other thermodynamics parameter, and closeness break out a machine experiment carry on a calculation was computed, it gets comprehensive combustion characteristic parameter, thus for study the physics and chemistry function that a certain double radicles push forward to provide reference.

\section{EXPERIMENT}

\subsection{Experiment instrument}

DSC 8000 to differ to show to scan quantity hot instrument of PE company in the United States; The closeness breaks out the machine essence as the thick wall steel system of the $100 \mathrm{ml}$ a tube. It is settled by mark, its capacity $\mathrm{V}_{0}=106.1 \mathrm{ml}$, the both ends uses to measure to press to fill head and point fire to fill a head to seal completely respectively.

\subsection{Condition of experiment}

$\mathrm{N} 2(99.999 \%)$, the air pressure is $0.3 \mathrm{MPa}$, dynamic state atmosphere, nitrogen current of air soon $20 \mathrm{ml} / \mathrm{min}$, common aluminum pond book side, heat velocity to distinguish to $5,10,15,20^{\circ} \mathrm{C} / \mathrm{min}$, sample quality was $2 \mathrm{mg}$.

\subsection{Material of experiment}

Push forward a certain double radicles place on heating in the constant temperature box in $85^{\circ} \mathrm{C}$, the aging time were $3,7,15,30$ and 50 days.

\section{RESULTS AND DISCUSSION}

\subsection{Hot decomposition of the double base propellant}

The double base propellant of aging $30 \mathrm{~d}$ in $85^{\circ} \mathrm{C}$ was done DSC test which is adopting different heat velocity, as figure 1 shows. From diagram we can see, under different heat velocity condition, start of temperature were mostly same of the double radicle propellant, $185^{\circ} \mathrm{C}$. Along hot decomposition process, it appeared only one peak temperature. And it can see that during the hot decomposition, the heat velocity bigger, the double radicle pushes forward putting of decomposition calories bigger, which explained that it influenced heat the hot decomposition process of the double base propellant. Figure 2 is the double radicle push forward of aging different time of the DSC diagram that is under the situation that heat the velocity as $15^{\circ} \mathrm{C} / \mathrm{min}$, it can see, along with 
the increment in aging time, DSC peak temperature of the curve moves toward heat direction, and its reaction calories is bigger.

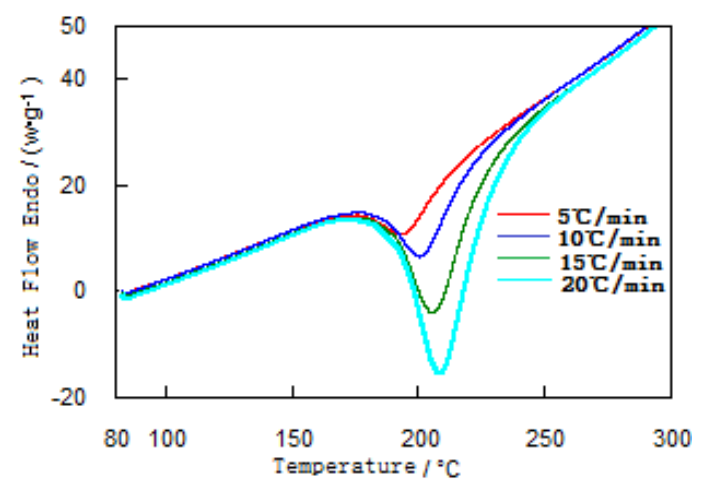

Fig1. The DSC diagram of dissimilarity heats velocity of aging $30 \mathrm{~d}$ in $85^{\circ} \mathrm{C}$.

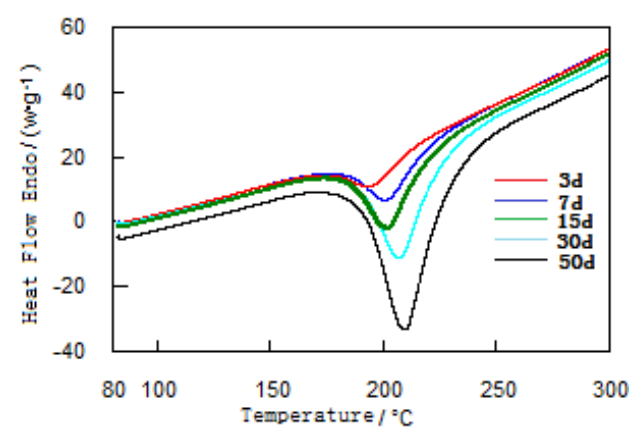

Fig2. The DSC diagram of $15^{\circ} \mathrm{C} / \mathrm{min}$

Carry on the DSC examination to aging different time of a certain double base push forward with the dissimilarity heats velocity, and make use of hot analysis dynamics to compute activate energy.

The hot decomposition process of contains ability material follows Arrhenius equation [HU R.Z,2009], namely:

$\tau=\mathrm{Ae}^{E_{a} / R T}$

Where: A is factor before pointing; $E_{a}$ is activate energy; $\mathrm{R}$ is the air of Mole measures, $8.314 \mathrm{~J} \cdot \mathrm{mol}^{-}$ $1 \cdot \mathrm{K}^{-1}$.

For this text of non-constant temperature DSC's data, usually adopt a Kissinger equation [Kissingeer H E. 1957], as follows:

$\ln \left(\frac{\beta}{T_{p}^{2}}\right)=\ln \frac{A R}{E_{a}}-\frac{E_{a}}{R T_{p}}$

Or equation of Ozawa:

$\lg \beta=\lg \left(\frac{A E_{a}}{R g(\alpha)}\right)-2.315-0.4567 \frac{E_{a}}{R T}$

Where: $\beta$ is heat velocity; $T_{\mathrm{p}}$ is peak temperature; $\mathrm{g}(\alpha)$ is the integral calculus form of mechanism function; $\alpha$ is responds depth.

While using Kissinger equation and Ozawa equation, it needs four velocity of differently heat velocity at least, thus this test adopts one of both equation to compute activate energy of the double base propellant, it is Ozawa equation.

In the Ozawa equation, $\lg \beta-\frac{1}{1}$ will be seen a linear function, $y=a x+b$, such as figture 2 shows.

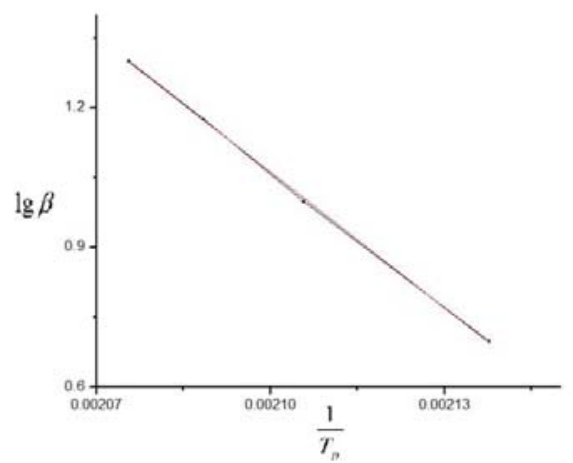

Fig3. The DSC diagram's peak temperature of aging 30 days with heat drawing up of velocity to match curve

According to drawing up to match the gradient of the curve gets to compute an aging 30 days of double radicle propellants activate energy is 158.3 $\mathrm{kJ} / \mathrm{mol}$. According to the Ozawa equation, Activating of all sample ability was computed, such as table 1 shows.

Tab1. Aging different time activating ability the double radicle propellant

\begin{tabular}{|c|c|c|c|c|c|c|}
\hline $\begin{array}{c}\text { Aging } \\
\text { time(d) }\end{array}$ & 0 & 3 & 7 & 15 & 30 & 50 \\
\hline $\mathrm{Ea}(\mathrm{kJ} / \mathrm{mol})$ & 176.8 & 175.8 & 174.8 & 169.9 & 158.3 & 153.0 \\
\hline
\end{tabular}

From table 1 we can see, at 0-7 days, activate ability descend slowly, Stability of the double base propellant Is slow-moving to become weak. But 715 day, descend trend of activating energy is obvious enlarge, that explains at this time, the stability of the double base propellant loss of the composition suddenly becomes big. Activating energy descend, but after of activate can get into slowness to descend trend again.

\subsection{A certain double radicles push forward the burnable function of}

Pressure and combustion time

Figure 4, figure 5 is dp/dt-t curve and P-t curve respectively.

From figure 4, the curve isn't ideal medium of smooth status, slightly motion, it explains that aging double base propellant cannot stabilize combustion in the burnable process. Aging made its inner part distribute to have a change in response to the dint, and the nitric turns fibrous member structure to encounter breakage.

According to figure 5, it can get a pair of radicles to push forward the output biggest pressure and 
combustion in a combustion process time, such as table 2 shows.

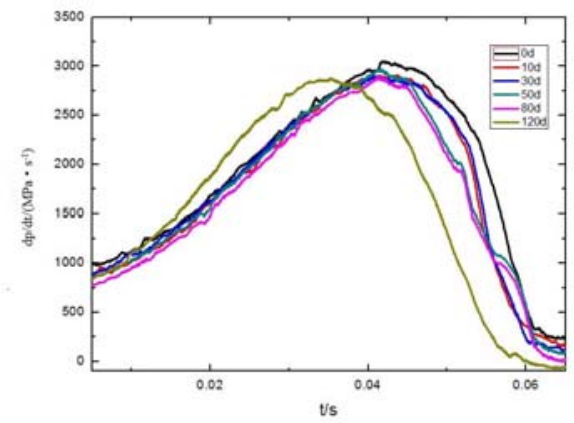

Fig.4 The dp/dt-t curve of low density packs

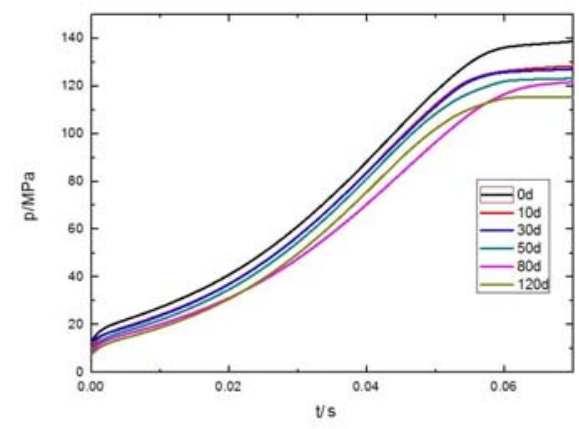

Fig.5 The P-t curve of low density packs

Tab.2 The biggest pressure of the double base propellant

\begin{tabular}{ccc}
\hline $\begin{array}{c}\text { Aging } \\
\text { time(d) }\end{array}$ & Pm/MPa & $\mathrm{t} / \mathrm{ms}$ \\
\hline 0 & 136.29 & 60.17 \\
3 & 126.13 & 58.61 \\
7 & 125.32 & 58.33 \\
15 & 121.51 & 59.74 \\
30 & 118.53 & 61.08 \\
50 & 115.27 & 59.95 \\
\hline
\end{tabular}

\section{CONCLUSIONS}

(1) Putting the double base propellant in $85^{\circ} \mathrm{C}$ to aging can know stability variety of the double base propellant in heat condition. With aging time longer, stability more descend of the double base propellant.

(2) It can judge stability of the double base propellant through compute activate energy of the double base propellant which is aging different time.

(3) The double base propellant after aging cannot stabilize combustion, its burnable speed let up gradually when aging time longer, explosive dint and remaining permits let up, it explains that aging make burnable function of radicles push forward descend.

\section{REFERENCE:}

Eric Baum. 2012. Mathew Richard Denision. Characterizan of solid propellants by damped combustion osillations. Combustion and flame, 159: 854-858

Ermolaev B S, Romankov A V, Sulimov, A A, et al. 2014. Compacted modified propellant blocks as traveling charge in the hybrid shot scheme plosives. Pyrotechnics, Explosive, Pyrotechnics, 6:881-889.

HU R.Z\& Gao S.L. 2008. Hot Analysis Dynamics. Beijing: Science publisher.

HU R.Z, MA H.X, ZHAO F.Q, et al. 2013. Studies on Thermal Safety and a Density Functional Theory of 2, 2, 2Trinitroethy-4, 4, 4-Trinitrobutyrate. Chinese Journal of Explosives \& Propellants, 36(5) :8-10.

HU R.Z, GAO H.X, ZHAO F.Q, et al. 2009. Theory and Numerical Method of Calculating the Kinetic Parameters of Exothermic Decomposition Reaction of Energetic Materials from Peak Temperature of DSC Curves at Constant Heating Rates. Chinese Journal of Energetic Materials, 17(6) :644646.

Kissingeer H E. 1957. Reaction kinetics in differential thermal analysis. Anal Chem, 29(11): 1702-1706.

LIU Z.R. 2008. Hot Analysis of Energetic Materials. Beijing: Defense industry publisher.

WANG X.J. 2011. Mechanism and Kinetics of Thermal Decomposition of Pazufloxacin Mesilate. Journal of Analytical Science, 27(3).

ZHAO B.M, LI X.L, LIU L.D, et al. 2015. Ignition powders of the three layers gun propellant based on RGD7A. Explosive Materials, 44(3):51-54. 